\title{
Body composition changes in bodybuilders: a method comparison
}

Citation for published version (APA):

van Marken Lichtenbelt, W. D., Hartgens, L. M. G., Vollaard, N. B., Ebbing, S., \& Kuipers, H. (2004). Body composition changes in bodybuilders: a method comparison. Medicine and Science in Sports and Exercise, 36(3), 490-497. https://doi.org/10.1249/01.MSS.0000117159.70295.73

Document status and date:

Published: 01/01/2004

DOI:

10.1249/01.MSS.0000117159.70295.73

Document Version:

Publisher's PDF, also known as Version of record

Document license:

Taverne

Please check the document version of this publication:

- A submitted manuscript is the version of the article upon submission and before peer-review. There can be important differences between the submitted version and the official published version of record.

People interested in the research are advised to contact the author for the final version of the publication, or visit the DOI to the publisher's website.

- The final author version and the galley proof are versions of the publication after peer review.

- The final published version features the final layout of the paper including the volume, issue and page numbers.

Link to publication

\footnotetext{
General rights Owners
rights.

- You may freely distribute the URL identifying the publication in the public portal. please follow below link for the End User Agreement:

www.umlib.nl/taverne-license

Take down policy

If you believe that this document breaches copyright please contact us at:

repository@maastrichtuniversity.nl

providing details and we will investigate your claim.
}

Copyright and moral rights for the publications made accessible in the public portal are retained by the authors and/or other copyright owners and it is a condition of accessing publications that users recognise and abide by the legal requirements associated with these

- Users may download and print one copy of any publication from the public portal for the purpose of private study or research.

- You may not further distribute the material or use it for any profit-making activity or commercial gain

If the publication is distributed under the terms of Article $25 \mathrm{fa}$ of the Dutch Copyright Act, indicated by the "Taverne" license above, 


\title{
Body Composition Changes in Bodybuilders: A Method Comparison
}

\author{
WOUTER D. VAN MARKEN LICHTENBELT ${ }^{1}$, FRED HARTGENS ${ }^{2,4}$, NIELS B. J. VOLLAARD ${ }^{5}$, \\ SPIKE EBBING ${ }^{3}$, and HARM KUIPERS ${ }^{2}$
}

${ }^{1}$ Department of Human Biology, ${ }^{2}$ Department of Movement Sciences, and ${ }^{3}$ Department of Internal Medicine, Maastricht University, THE NETHERLANDS; ${ }^{4}$ Netherlands Centre for Doping Affairs, Capelle aan de IJssel, THE NETHERLANDS; and ${ }^{5}$ Department of Biological Sciences, Centre for Sport and Exercise Sciences, Colchester, UNITED KINGDOM

\begin{abstract}
VAN MARKEN LICHTENBELT, W. D., F. HARTGENS, N. B. J. VOLLAARD, S. EBBING, and H. KUIPERS. Body Composition Changes in Bodybuilders: A Method Comparison. Med. Sci. Sports Exerc., Vol. 36, No. 3, pp. 490-497, 2004. Introduction: Few studies report on validation of body composition changes using the four-compartment model (4C), and no such studies are available in strength training. Here we present such a validation study for the determination of body fat and fat-free mass changes in bodybuilders, who used exercise and androgenic-anabolic steroids. Methods: The study was carried out with 27 male bodybuilders in a crosssectional study. Fifteen of these subjects also participated in an intervention program where body composition changes were measured. The 4C model served as the gold standard. The alternative mechanistic methods were underwater weighing (uww), deuterium dilution (dil), three-compartment model incorporating total body water $(3 \mathrm{Cw})$, three-compartment model incorporating bone mineral content $(3 \mathrm{Cb})$, and descriptive methods, namely dual-energy x-ray absorptiometry (DXA), prediction equations based on body mass index (BMI), skinfold measurement, and bioimpedance analyses. Results: From the cross-sectional study, it appeared that biases and errors of most mechanistic methods were small (maximal $0.5 \% \mathrm{BF}$ and $3.4 \% \mathrm{BF}$, respectively; exception $3 \mathrm{Cb}$ model). The $3 \mathrm{Cw}$ model had the lowest error $(0.9 \% \mathrm{BF})$. The descriptive methods had small biases (exception BMI) but relatively large errors (range: 5.5-8\%). Results on body composition changes (intervention study) were comparable with the results from the cross-sectional study. Conclusions: Using the $4 \mathrm{C}$ model as the standard for determination of body fat and fat-free mass, this study revealed that apart from the prediction equation based on $\mathrm{BMI}$ and the $3 \mathrm{Cb}$ model, all methods gave acceptable group mean values. When accurate measurements on body composition and/or body composition changes on an individual level are needed, only the $3 \mathrm{Cw}$ model could serve as an alternative for the 4C method. Key Words: ANDROGENIC-ANABOLIC STEROIDS, STRENGTH TRAINING, FOUR COMPARTMENT MODEL, DEUTERIUM DILUTION, DXA
\end{abstract}

$\mathrm{M}$ easuring changes in body composition is an important tool to monitor the efficacy of physical training. Knowledge of body composition may also serve as a tool for the assessment of energy and nutrient requirements. Determination of body composition covers many different components, ranging from body fat, water compartments, and cell mass to bone minerals. It is important to be aware of the underlying assumptions the various techniques are based on, as these postulations determine to a large extent the accuracy of the body component measurements under study $(16,23)$.

In sports, the main interests are body mass (BM) and body composition based on the two-compartment model (2C): fat mass (FM) and fat-free mass (FFM). Until

\footnotetext{
Address for correspondence: W. D. van Marken Lichtenbelt, Department of Human Biology, Maastricht University, P. O. Box 616, 6200 MD Maastricht, The Netherlands; E-mail: MarkenLichtenbelt@HB.unimaas.nl. Submitted for publication March 2003.

Accepted for publication October 2003.
}

0195-9131/04/3603-0490

MEDICINE \& SCIENCE IN SPORTS \& EXERCISE E $_{\circledast}$

Copyright (C) 2004 by the American College of Sports Medicine

DOI: $10.1249 / 01 . M S S .0000117159 .70295 .73$ recently, hydrodensitometry (underwater weighing) has been used as the gold standard for determination of percentage body fat $(\% \mathrm{BF})$. This method, however, assumes fixed densities of FM and FFM, whereas individuals may have different FFM densities due to specific hydration of the FFM and/or variation in the amount of bone minerals. These may depend on age, disease, exercise training, nutrition, and medication (16). One of the best methods for determining the body composition presently available is the so-called four-component (4C) model (7). The 4C model incorporates measurements of total body water (by deuterium dilution), total bone mineral content (BMC, by DXA), as well as body density (for instance, by underwater weighing) (14). Thus, fewer assumptions are made than with hydrostatic weighing alone, which results in a more accurate determination of FFM. Moreover, the 4C model enables the calculation of FFM hydration (9).

The choice of the method depends (apart from financial aspects) on accuracy and invasiveness. All body composition methods are indirect methods. We subdivide the methods into mechanistic or descriptive ones (23). Mechanistic methods, also called biological methods, have a functional relation to a known component. These methods include 
densitometry, dilution techniques, three-compartment (3C), and $4 \mathrm{C}$ models.

All descriptive methods are based on prediction equations with a mechanistic reference method within a well-characterized population. Descriptive methods, therefore, are often population specific (e.g., 4), and for each population the methods need to be validated. Furthermore, the method includes both errors related to the measurement itself and errors of the reference method. In general, advantages of the descriptive methods are that they are relatively inexpensive, fast, and noninvasive compared with the more elaborate mechanistic methods. Well-known descriptive methods are based on measurements of body mass index (BMI), skinfolds, bioimpedance analyses, and dual x-ray absorptiometry (DXA) (when used to determine body fat). Clearly, in sports, the noninvasive and fast methods like skinfolds and bioimpedance are popular.

Many validation studies have been presented in the past, comparing different methods, using underwater weighing as the gold standard. However, few studies have been presented using the 4C model as the gold standard, and hardly any validation studies are available for the measurement of body composition changes.

Here we present a validation study on body composition and body composition changes in bodybuilders, who used exercise and androgenic-anabolic steroids with the intention to reduce $\mathrm{FM}$ and increase muscle mass. The $4 \mathrm{C}$ model served as the gold standard. The alternative methods that were compared with the 4C model were: underwater weighing (uww), deuterium dilution (dil), DXA, the 3C model incorporating total body water $(3 \mathrm{Cw}$, see below), the $3 \mathrm{C}$ model incorporating bone minerals ( $3 \mathrm{Cb}$, see below), BMI, skinfolds, and bioimpedance.

\section{METHODS}

\section{Approach to the Problem and Experimental Design}

This study was part of a larger project investigating the effects of androgenic-anabolic steroids (AAS) on body composition and health status in strength athletes. Here we report on the effects on body composition. To meet the number of volunteers needed for our studies, we recruited a large number of strength athletes. The total number of athletes who wanted to participate in one or more studies was about 90 . Before admission to the studies, all volunteers underwent a full medical examination. Only one athlete was not admitted to the study for medical reasons.

To meet the objectives outlined above for the body composition method comparisons, we performed two studies. Using a cross-sectional design, we performed a validation study on body composition measurements applying different methods and using the $4 \mathrm{C}$ model as the gold standard (study 1). In this study, body compositions were determined in 27 bodybuilders by the different methods described below.
Additionally, in a longitudinal design, we aimed to validate different methods of body composition determinations for the measurement of body composition changes during a strength-training period that was accompanied by the use of AAS. Again the 4C model served as the gold standard (study 2). Fifteen subjects of study 1 were willing to participate in study 2 and underwent body composition measurements at baseline and after 8 wk of strength training and of AAS administration.

\section{Subjects}

Before admission to the study, the subjects had to meet all the criteria set by the investigators: male sex, strengthtraining experience for a minimum of $3 \mathrm{yr}$, at least four strength-training workouts per week or 8-h strength training weekly, and age between 20 and $45 \mathrm{yr}$. The following exclusion criteria were used: hypertension, diabetes mellitus, liver disease or abnormal liver enzyme serum levels, hereditary hypercholesterolemia, elevated serum cholesterol $\left(>6.5 \mathrm{mmol} \cdot \mathrm{L}^{-1}\right)$, infertility, and smoking.

All athletes had to fill out an extensive questionnaire with questions related to current and previous health status, training habits and history, dietary intake, and the use of nutritional supplements and AAS. In individual interviews with a physician (F.H.), the questionnaires were examined to obtain complete and correct data. In addition, the physician performed a full medical examination for evaluation of the health status and to exclude any relevant disease conditions. Only volunteers who appeared to be healthy and who met all criteria set by the investigators were admitted to the study.

The study was approved by the Medical Ethical Review Committee of the Maastricht University and the University Hospital Maastricht. Before entering the study, every subject gave his written informed consent.

\section{Strength Training and AAS Administration}

The subjects who participated in study 2 continued their regular strength-training regimen (approximately 8-9 $\mathrm{h} \cdot \mathrm{wk}^{-1}$ ) during the study period. With respect to the administration of AAS, two different protocols were applied that were in accordance with the design of the larger study investigating the effects of AAS on body composition and health. In a randomized, placebo-controlled study, 16 bodybuilders received weekly intramuscular injections of nandrolone decanoate $\left(200 \mathrm{mg} \cdot \mathrm{wk}^{-1}\right)$ or placebo. The 16 bodybuilders underwent the different body composition measurements as described below at baseline and after an 8 -wk intervention period. However, for the validation of body composition assessment methods to determine of body composition changes, only the nine subjects who received nandrolone decanoate were included in study 2. Additionally, six strength athletes who intended to self-administer cocktails of oral and intramuscular AAS simultaneously were also included in study 2 . 


\section{Body Composition Measurements}

Prediction equation using BMI. Body fat percentage was calculated by a prediction equation based on body mass index (BMI), age and gender (5):

$$
\% \mathrm{BF}=1.20 \times \mathrm{BMI}+0.23 \times \mathrm{Age}-10.8 \times \mathrm{sex}-5.4
$$

(BMI in $\mathrm{kg} \cdot \mathrm{m}^{-2}$, age in years, sex: male: 1$)$

Skinfold thickness. With a Harpenden caliper (Harpenden, Pembrokeshire, UK) skinfold thickness was measured from triceps, biceps, subscapular, and suprailiac. Body density $(\mathrm{Db})$ was calculated using the Durnin and Womersley equation (6). Percent body fat was calculated using the equation from Siri (22): $\% \mathrm{BF}=(4.95 / \mathrm{Db}+$ $4.50) \times 100$. The mean result of two measurements was used.

Bioimpedance spectrometry. Single frequency bioimpedance (SF-BIA) was measured at $50 \mathrm{kHz}$, using Xitron 4000B bioimpedance analyses in a tetrapolar arrangement of gel electrodes placed on hand, wrist, ankle, and foot at the right side of the body (18). FFM was calculated using a prediction equation $\left(\mathrm{FFM}=0.756 \mathrm{~S}^{2} / \mathrm{R}+0.11 \mathrm{~W}+0.107\right.$ $\mathrm{Xc}-5.463$, where S: stature, R: resistance, $\mathrm{W}$ : weight, and Xc: reactance) (15).

Densitometry. Whole-body density was determined by underwater weighing in the fasted state. Body mass in air and underwater was determined on a digital balance, accurate to $0.01 \mathrm{~kg}$ (Sauter type E1200). Lung volume was measured simultaneously with the helium dilution technique using a spirometer (Volugraph 2000, Mijnhardt, The Netherlands). Body density was used to calculate body fat according to the two- and multi-compartment models (see below).

Deuterium dilution. Subjects received an orally administered dose of $\mathrm{D}_{2} \mathrm{O}$ of $0.1 \mathrm{~g} \cdot \mathrm{L}^{-1}$ estimated TBW between 22:00 and 23:00 h (24). Total body water was in first instance estimated from the formula of Deurenberg et al. (5). The appropriate amount of $\mathrm{D}_{2} \mathrm{O}(99.8 \%$, Akademie der Wissenschaften, Leipzig, Germany) was weighed out and diluted with tap water to $0.075 \mathrm{~L}$ for intake. $\mathrm{D}_{2} \mathrm{O}$ enrichment in the body fluid was measured in urine. Before dose administration, background urine samples were taken. Urine samples were taken $10 \mathrm{~h}$ after dose administration after an overnight fast from the second voiding. Isotope abundances in urine were determined in duplicate with an isotope-ratio mass spectrometer (Aqua Sira, VG Isogas, Cheshire, UK). Total body water (TBW) was calculated as the deuterium dilution space divided by 1.04 , correcting for exchange of the deuterium label with nonaqueous hydrogen of body solids (21). FFM was calculated by: (BM-TBW/0.73)/BM $\times 100 \%$.

Dual energy x-ray absorptiometry. Total BMC (TBMC) and total BMD (TBMD) were determined by a whole-body dual-energy x-ray absorptiometer (DPX-L, Lunar Corp., Madison, WI) (19). We used the fast scan speed with a resolution of $4.8 \times 9.6 \mathrm{~mm}$ (whole body). Bone content and density were calculated by Lunar software (version 1.3z). For the whole-body scan, the subject laid in a supine position. The results were compared with the Ger- many Total Body White Reference Population provided by the manufacturer.

Body composition models. The multi-compartment models in this study used body density as one property. Underwater weighing is, therefore, the common technique. In the multi-compartment models, body water and bone mineral mass are determined independently. Water mass (TBW, $\mathrm{kg}$ ) is determined by deuterium dilution, and bone mineral mass (TBMC, $\mathrm{kg}$ ) by DXA. Total body mineral mass $(\mathrm{MM})$ is: $\mathrm{MM}=\mathrm{TBMC} / 0.824$.

The multi-compartment equations are based on the same premise as the $2 \mathrm{C}$ model, that is, that body volume is the sum of separate compartment volumes.

Body fat percentages were calculated in different ways:

For the classical two-component model (2C), the equation of Siri was used (22):

$$
\% \mathrm{BF}=\left(4.95 \cdot \mathrm{Db}^{-1}-4.5\right) \times 100
$$

For the three-component model with water $(3 \mathrm{Cw})$, another equation proposed by Siri was used (22):

$$
\% \mathrm{BF}=(2.118 / \mathrm{Db}-0.78 \times \mathrm{TBW} / \mathrm{BM}-1.354)-100
$$

For the three-component model with body minerals $(3 \mathrm{Cb})$, an equation by Lohman was applied (14):

$$
\% \mathrm{BF}=(6.386 / \mathrm{Db}+(3.961 \times \mathrm{TBMC}) /(0.824 \times \mathrm{BM})-6.090)
$$

The 4C model used an equation proposed by Lohman also (14): $\% \mathrm{BF}=(2.747 / \mathrm{Db}-0.714 \times \mathrm{TBW} / \mathrm{BM}+1.146 \times$

$$
\mathrm{TBMC} / \mathrm{BM}-2.0503) \times 100
$$

Hydration of the FFM was calculated according to Fuller (8):

$$
\text { Hydration fraction }=\text { TBW/FFM, }
$$

where TBW is determined by $\mathrm{D}_{2} \mathrm{O}$ dilution, and FFM by the $4 \mathrm{C}$ model.

Density of the FFM was calculated as follows, also according to Fuller et al. (8):

$\mathrm{DFFM}=1 /(\mathrm{TBW} / \mathrm{FFM} / \mathrm{dw}+\mathrm{TBMC} / 0.824 / \mathrm{FFM} / \mathrm{dm}$

$$
+\operatorname{protein} / \mathrm{FFM} / \mathrm{dp}) \text {, }
$$

where protein $=\mathrm{FFM}-\mathrm{TBW}-\mathrm{MM}$, and dw, dm, and dp represent the densities of the water-, mineral-, and proteincomponent, namely, $0.9937,3.038,1.34 \mathrm{~g} \cdot \mathrm{mL}^{-1}$ according to Brozek et al. (2).

\section{Statistical Analyses}

Results are expressed as mean values and ranges. Effect size of FFM was calculated by subtracting the mean after the use of AAS from the mean at baseline, divided by the standard deviation at baseline. For the $4 \mathrm{C}$ model, the effect size of FFM was 0.44. Pearson correlation coefficients were calculated to test relations between differences in \%BF estimates of different methods/models and bone mass densities. The bias (average difference between alternative methods $)$ and error $(2 \times$ standard deviations) between the different methods were calculated according to the method 
TABLE 1. Physical characteristics and results of body composition calculations at baseline $(N=27)$.

\begin{tabular}{|c|c|c|c|}
\hline & \multicolumn{3}{|c|}{ Baseline } \\
\hline & Mean & SD & Range \\
\hline Age (yr) & 31.8 & & $19.0-44.0$ \\
\hline Height (cm) & 176 & 7.6 & $161-188$ \\
\hline $\mathrm{BM}(\mathrm{kg})$ & 79.7 & 10.7 & $54.5-100.3$ \\
\hline $\mathrm{BMI}\left(\mathrm{kg} \cdot \mathrm{m}^{-2}\right)$ & 25.6 & 2.5 & $21.0-31.7$ \\
\hline Hydration FFM & 0.725 & 0.010 & $0.707-0.757$ \\
\hline Density FFM $\left(\mathrm{kg} \cdot \mathrm{L}^{-1}\right)$ & 1.100 & 0.004 & $1.091-1.107$ \\
\hline Mineral density FFM $\left(\mathrm{kg} \cdot \mathrm{L}^{-1}\right)$ & 0.065 & 0.005 & $0.055-0.79$ \\
\hline TBMD $\left(\mathrm{g} \cdot \mathrm{cm}^{-2}\right)$ & 1.28 & 0.09 & $1.11-1.48$ \\
\hline \multicolumn{4}{|l|}{$\% \mathrm{BF}$} \\
\hline BMI & 21.9 & 3.6 & $13.4-28.9$ \\
\hline SF & 16.7 & 4.1 & $7.5-30.0$ \\
\hline $\mathrm{BIA}$ & 15.6 & 4.4 & $6.6-25.3$ \\
\hline DXA & 17.4 & 4.7 & $8.8-26.4$ \\
\hline $\mathrm{D}_{2} \mathrm{O}$ & 17.1 & 3.9 & $7.8-23.5$ \\
\hline UWW (2C) & 16.5 & 4.1 & $9.4-23.6$ \\
\hline $3 \mathrm{Cw}$ & 17.0 & 3.8 & $8.7-23.1$ \\
\hline $3 \mathrm{Cb}$ & 13.2 & 4.4 & $3.1-22.0$ \\
\hline $4 C$ & 16.6 & 3.8 & $7.5-23.2$ \\
\hline \multicolumn{4}{|l|}{ FFM (kg) } \\
\hline BMI & 62.0 & 6.9 & $47.2-72.0$ \\
\hline SF & 66.2 & 8.4 & $49.2-81.0$ \\
\hline BIA & 67.1 & 8.5 & $47.5-85.5$ \\
\hline DXA & 65.5 & 7.0 & $48.2-78.5$ \\
\hline $\mathrm{D}_{2} \mathrm{O}$ & 65.8 & 7.6 & $47.1-77.8$ \\
\hline UWW (2C) & 66.4 & 8.4 & $46.7-81.2$ \\
\hline $3 \mathrm{Cw}$ & 66.0 & 7.4 & $46.8-79.3$ \\
\hline $3 \mathrm{Cb}$ & 69.1 & 8.9 & $48.6-84.5$ \\
\hline $4 C$ & 66.3 & 8.0 & $47.1-79.8$ \\
\hline
\end{tabular}

described by Altman and Bland (1). One group, two-tailed, $t$-tests were used to test whether a bias was significantly different from zero. A paired, two-tailed $t$-test was used to establish whether the TBMD values measured in our study population were significantly different from age matched reference values. The $P$ value required for significance was set at $P<0.05$.

Power analyses ( $\beta=0.80, \alpha=0.02)$ for FFM by the 4C model revealed that with a within-subject standard deviation of $1.3 \mathrm{~kg}$ and an expected difference of $2 \mathrm{~kg}$, the minimal number of subjects needed was five (one-tailed).

\section{RESULTS}

Cross-sectional study. Age of the volunteers ranged from 19 to $44 \mathrm{yr}$, and body mass ranged from 54.5 to 100.3 $\mathrm{kg}$ with BMI of $21.0-31.7 \mathrm{~kg} \cdot \mathrm{m}^{-2}$ (Table 1). Total BMD was significantly higher than that of the age-matched reference population provided by the software of the DXA machine ( $t$-test $P<0.05$ ). In addition, TBMD was significantly related to the body mass (Fig. 1). The mean hydration of the FFM was $72.5 \%$, but individual values ranged from 0.71 to 0.76 .

In our study population of using bodybuilders, body fat by the criterion method ( $4 \mathrm{C}$ model) was on average $16.6 \%$. Results from the other methods sometimes deviated substantially from this reference value (Table 1). The highest $\% \mathrm{BF}$ was obtained from the prediction equation based on BMI measurements (21.9\%). The 3Cb model resulted in the lowest $\% \mathrm{BF}$ of $13.2 \%$. Body fat values calculated by the alternative methods significantly correlated with the values from the 4C model (Table 2).

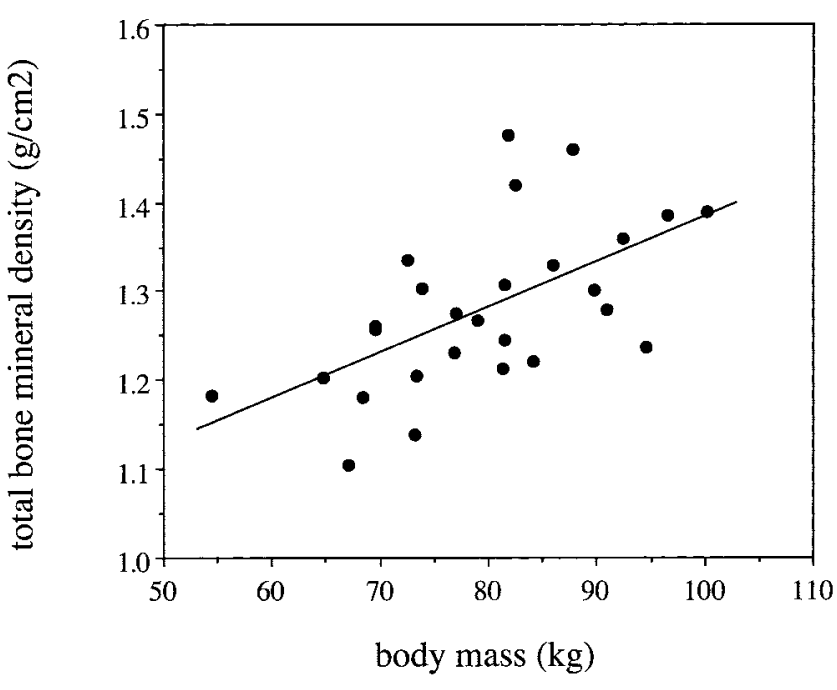

FIGURE 1-Total BMD (TBMD) in relation to body mass (TBMD = $\left.0.005 \cdot B M+0.88, R^{2}=0.35, P<0.02\right)$. Data from the cross-sectional study.

Bland and Altman (1) analyses revealed that most differences in \%BF between the alternative methods and the $4 \mathrm{C}$ model were not significantly related to the size of the measured compartment (Table 2). Two examples of a Bland and Altman plot are given for \%BF, either calculated by the prediction equation based on BMI measurements (Fig. 2A) or by the $3 \mathrm{Cw}$ model (Fig. 2B). These examples show that the difference between the two methods (BMI and 4C model, and 3Cw model and 4C model, respectively) is not related to the size of the compartment (mean value between $\mathrm{BMI}$ and $4 \mathrm{C}$ model, and $3 \mathrm{Cw}$ model and $4 \mathrm{C}$ model, respectively). Bias (average difference) and error $(2 \times$ standard deviation $)$ are much larger for the BMI-based method than for the $3 \mathrm{Cw}$ model. For the $3 \mathrm{Cb}$ model, a significant relationship was observed between

TABLE 2. Results from regression analyses comparing \%BF and FFM calculated by the reference method ( $4 \mathrm{C}$ model) and the alternative methods in a cross-sectional study; results of the Altman and Bland analyses are given as well.

\begin{tabular}{|c|c|c|c|c|c|c|}
\hline & \multicolumn{2}{|c|}{$\begin{array}{c}\text { Regression } \\
\text { Analyses }\end{array}$} & \multicolumn{3}{|c|}{ Altman and Bland Analyses } & \multirow[b]{2}{*}{$P$} \\
\hline & $\mathbf{R}$ & $P$ & Bias & Error (2 SD) & $\mathbf{R}$ & \\
\hline \multicolumn{7}{|l|}{$\% B F$} \\
\hline BMI & 0.61 & 0.001 & $5.33^{*}$ & 6.59 & - & NS \\
\hline Skinfolds & 0.5 & 0.01 & 0.17 & 7.92 & - & NS \\
\hline BIA & 0.5 & 0.01 & -0.94 & 8.12 & - & NS \\
\hline DXA & 0.82 & 0.0001 & 0.85 & 5.45 & - & NS \\
\hline $\mathrm{D}_{2} \mathrm{O}$ dilution & 0.95 & 0.0001 & 0.54 & 3.39 & - & NS \\
\hline UWW (2C) & 0.94 & 0.0001 & -0.07 & 2.69 & - & NS \\
\hline $3 \mathrm{Cw}$ & 0.99 & 0.0001 & $0.44^{*}$ & 0.90 & - & NS \\
\hline $3 \mathrm{Cb}$ & 0.93 & 0.0001 & $\left(-3.40^{*}\right.$ & 3.24) & 0.39 & 0.05 \\
\hline \multicolumn{7}{|l|}{ FFM } \\
\hline BMI & 0.94 & 0.0001 & $\left(-4.31^{*}\right.$ & $5.46)$ & 0.41 & 0.03 \\
\hline Skinfolds & 0.93 & 0.0001 & -0.11 & 6.13 & & \\
\hline BIA & 0.92 & 0.0001 & 0.76 & 6.56 & & \\
\hline DXA & 0.97 & 0.0001 & $(-0.82$ & 4.44) & 0.45 & 0.05 \\
\hline $\mathrm{D}_{2} \mathrm{O}_{\text {dilution }}$ & 0.99 & 0.0001 & $(-0.47$ & 1.91) & 0.41 & 0.05 \\
\hline UWW (2C) & 0.99 & 0.0001 & $0.09^{\star}$ & 2.17 & & \\
\hline 3Cw & 0.99 & 0.0001 & $-0.35^{\star}$ & 0.72 & & \\
\hline $3 \mathrm{Cb}$ & 0.99 & 0.0001 & $(2.75$ & 2.76) & -0.61 & 0.001 \\
\hline
\end{tabular}

* Bias statistically significant different from zero $(P<0.05$, one-group two-tailed t-test). 

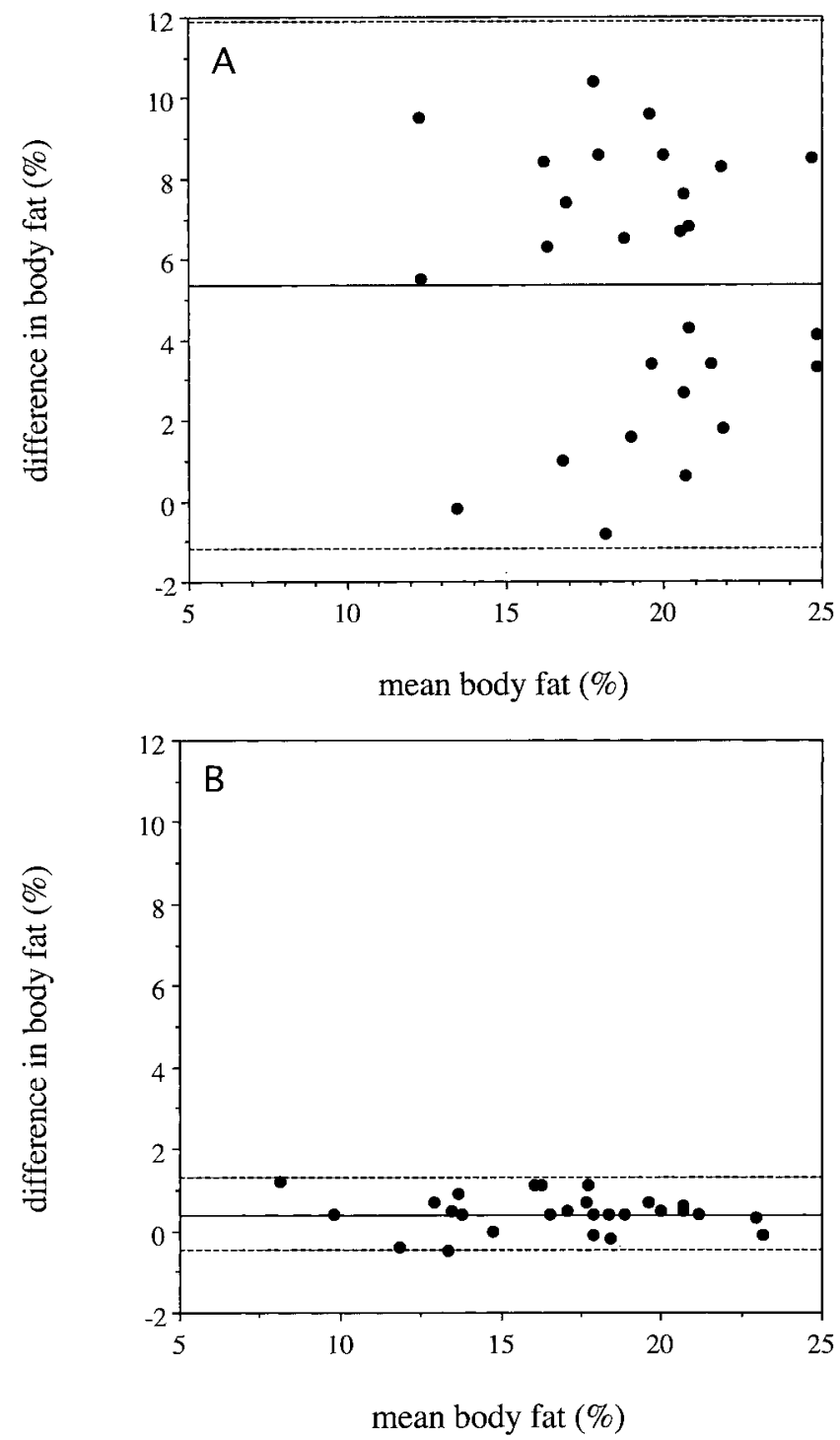

FIGURE 2-A. Bland and Altman plot of \%BF calculated with the prediction equation based on $\mathrm{BMI}$ and with the reference method $(4 \mathrm{C}$ model). For each subject the difference in outcomes between the methods is plotted against the mean values of both methods. The full line indicates the bias (mean outcome difference between both methods) and the dotted lines the error (2 SD). B. Bland and Altman plot of \% BF results based on the $3 \mathrm{Cw}$ model and the reference method (4C model).

the outcome differences with the standard $4 \mathrm{C}$ model and the mean \%BF (Table 2; $P<0.05$ ). Strictly taken, in such a case, calculations of bias and error are not allowed. However, the bias and error values are still indicative of the deviation from the gold standard one may expect within the measured range. Therefore, these values are put between brackets in Tables 2 and 4 .

The \% BF bias was largest for the BMI-based model $(5.33 \%)$ and lowest for the $2 \mathrm{C}$ and $3 \mathrm{C}$ models $(-0.07 \%)$ and skinfold measurements $(-0.17 \%)$. The error of the latter, however, was one of the largest together with the error of the BIA-based model (7.92\% and 8.12\%, respectively, Fig. 3). The lowest error was obtained with the $3 \mathrm{Cw}$ model $(0.90 \%)$. Biases were significantly different from zero for the BMI-, $\mathrm{D}_{2} \mathrm{O}-, 3 \mathrm{Cw}-$, and $3 \mathrm{Cb}$ - models. The methodological or phys-
TABLE 3. Physical characteristics and results of body composition calculations at baseline and after intervention $(N=15)$.

\begin{tabular}{|c|c|c|c|c|c|c|c|}
\hline & \multicolumn{3}{|c|}{ Baseline } & \multicolumn{3}{|c|}{ Intervention } & \multirow{2}{*}{$\begin{array}{c}\text { Change } \\
\text { Mean }\end{array}$} \\
\hline & Mean & SD & Range & Mean & SD & Range & \\
\hline Age (yr) & 31.5 & & $19.0-44.0$ & & & & \\
\hline Height (cm) & 176 & 8 & $161-188$ & & & & \\
\hline $\mathrm{BM}(\mathrm{kg})$ & 77.8 & 11.7 & $54.5-100.3$ & 80.6 & 11.0 & $57.6-100.1$ & 2.8 \\
\hline BMI $\left(\mathrm{kg} \cdot \mathrm{m}^{2}\right)$ & 25.0 & 2.9 & $21.0-31.7$ & 25.9 & 2.6 & $22.2-31.6$ & 0.9 \\
\hline Hydration FFM & 0.727 & 0.011 & $0.712-0.757$ & 0.724 & 0.013 & $0.701-0.746$ & \\
\hline $\begin{array}{c}\text { Density FFM } \\
\left(\mathrm{kg} \cdot \mathrm{L}^{-1}\right)\end{array}$ & 1.099 & 0.004 & $1.091-1.107$ & 1.099 & 0.005 & $1.091-1.108$ & \\
\hline $\begin{array}{l}\text { Mineral density } \\
\text { FFM }\left(\mathrm{kg} \cdot \mathrm{L}^{-1}\right)\end{array}$ & 0.065 & 0.006 & $0.055-0.79$ & 0.062 & 0.005 & $0.053-0.77$ & \\
\hline TBMD $\left(\mathrm{g} \cdot \mathrm{cm}^{-2}\right)$ & 1.27 & 0.09 & $1.14-1.48$ & 1.26 & 0.07 & $1.14-1.43$ & \\
\hline \multicolumn{8}{|l|}{$\% \mathrm{BF}$} \\
\hline BMI & 21.1 & 4.4 & $13.4-28.9$ & 22.2 & 4.0 & $14.8-28.8$ & 1.1 \\
\hline SF & 16.1 & 5.1 & $7.5-30$ & 14.9 & 4.2 & $8.6-25.5$ & -1.3 \\
\hline BIA & 15.1 & 4.2 & $6.6-20.5$ & 15.0 & 3.5 & $9.3-21.2$ & -0.1 \\
\hline DXA & 16.9 & 4.7 & $8.8-24.0$ & 15.1 & 3.6 & $9.3-19.7$ & -1.8 \\
\hline $\mathrm{D}_{2} \mathrm{O}$ & 16.2 & 4.6 & $7.8-22.5$ & 15.0 & 4.7 & $7.0-21.3$ & -1.2 \\
\hline UWW (2C) & 16.1 & 4.4 & $9.4-23.6$ & 14.5 & 3.7 & $7.2-20.9$ & -1.7 \\
\hline $3 \mathrm{CW}$ & 16.3 & 4.3 & $8.7-23.1$ & 15.0 & 4.0 & $8.5-21.3$ & -1.3 \\
\hline $3 \mathrm{Cb}$ & 12.8 & 4.9 & $3.1-22.0$ & 10.5 & 4.5 & $1.2-18.5$ & -2.3 \\
\hline 4C & 15.9 & 4.4 & $7.5-23.2$ & 14.4 & 4.1 & $7.2-21.1$ & -1.6 \\
\hline \multicolumn{8}{|l|}{ FFM $(\mathrm{kg})$} \\
\hline BMI & 61.1 & 7.0 & $47.2-72.0$ & 62.4 & 6.8 & $49.0-72.8$ & 1.4 \\
\hline SF & 65.1 & 9.1 & $49.2-81.0$ & 68.4 & 8.8 & $51.6-82.3$ & 3.4 \\
\hline BIA & 65.8 & 8.5 & $47.5-85.5$ & 68.3 & 8.2 & $50.2-83.7$ & 2.4 \\
\hline DXA & 64.3 & 7.4 & $48.2-78.5$ & 68.2 & 8.2 & $49.9-80.3$ & 3.9 \\
\hline $\mathrm{D}_{2} \mathrm{O}$ & 65.0 & 8.1 & $47.1-77.8$ & 68.3 & 8.6 & $48.8-78.8$ & 3.3 \\
\hline UWW (2C) & 65.1 & 8.9 & $46.7-81.2$ & 68.8 & 9.3 & $50.5-84.8$ & 3.7 \\
\hline $3 \mathrm{Cw}$ & 64.9 & 8.5 & $46.8-79.3$ & 68.4 & 8.8 & $49.5-81.4$ & 3.4 \\
\hline $3 \mathrm{Cb}$ & 67.7 & 9.5 & $48.6-84.5$ & 72.0 & 9.9 & $53.2-89.0$ & 4.4 \\
\hline $4 C$ & 65.2 & 8.6 & $47.1-79.8$ & 68.9 & 8.9 & $50.0-82.3$ & 3.7 \\
\hline
\end{tabular}

iological significance depends on the size of the bias in combination with the error. For instance, the bias of $\% \mathrm{BF}$ by BMI is significant because of the magnitude of the bias despite the large error. The small bias of $\% \mathrm{BF}$ by $3 \mathrm{Cw}$ is significant due to the very small error (see Fig. 2B and 3). The results from the $3 \mathrm{Cb}$ model revealed a much larger bias and error than those from the $3 \mathrm{Cw}$ model. There was a

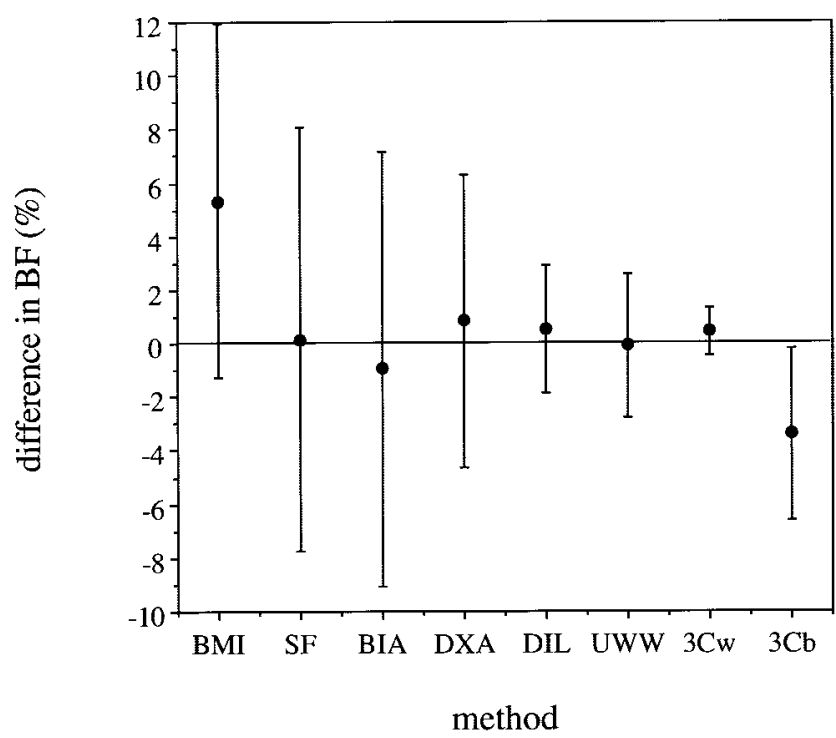

FIGURE 3-Mean difference (dots) between the cross-sectional \% BF values as calculated by the $4 \mathrm{C}$ model and the alternative methods and their errors (2 SD; vertical line). BMI, body mass index; SF, skinfolds; BIA, bioimpedance; DXA, dual x-ray absorptiometry; dil, dilution by deuterium; uww, underwater weighing; $3 \mathrm{Cw}$, three-component model with body water; $3 \mathrm{Cb}$, three-component model with body minerals. 
TABLE 4. Results from regression analyses comparing \%BF and FFM changes after intervention calculated by the reference method (4C model) and the by alternative methods; results of the Altman and Bland analyses are given as well.

\begin{tabular}{|c|c|c|c|c|c|c|}
\hline & $\begin{array}{r}\text { Reg } \\
\text { An }\end{array}$ & $\begin{array}{l}\text { ession } \\
\text { lyses }\end{array}$ & Altma & and Bland An & yses & \\
\hline & $\mathbf{R}$ & $P$ & Bias & Error (2 SD) & $\mathbf{R}$ & $P$ \\
\hline$\% B F$ & & & & & & \\
\hline BMI & - & NS & $\left(2.61^{*}\right.$ & 3.71) & 0.65 & 0.01 \\
\hline Skinfolds & 0.56 & 0.05 & 0.29 & 3.04 & - & NS \\
\hline $\mathrm{BIA}$ & 0.55 & 0.05 & 1.52 & 6.28 & - & NS \\
\hline DXA & 0.52 & 0.05 & -0.21 & 3.77 & - & NS \\
\hline $\mathrm{D}_{2} \mathrm{O}$ dilution & 0.72 & 0.0001 & 0.38 & 3.11 & - & NS \\
\hline UWW (2C) & 0.84 & 0.0001 & -0.09 & 2.39 & - & NS \\
\hline $3 \mathrm{CW}$ & 0.98 & 0.0001 & $0.26^{*}$ & 0.69 & - & NS \\
\hline $3 \mathrm{Cb}$ & 0.65 & 0.01 & $(-0.76$ & 3.91) & 0.55 & 0.05 \\
\hline FFM & & & & & & \\
\hline BMI & 0.76 & 0.001 & $\left(-2.28^{*}\right.$ & $3.28)$ & -0.81 & 0.001 \\
\hline Skinfolds & 0.88 & 0.0001 & -0.29 & 2.27 & - & NS \\
\hline $\mathrm{BIA}$ & - & NS & -1.14 & 5.16 & - & NS \\
\hline DXA & 0.77 & 0.001 & 0.22 & 3.11 & - & NS \\
\hline $\mathrm{D}_{2} \mathrm{O}$ dilution & 0.90 & 0.0001 & -0.32 & 2.53 & - & NS \\
\hline UWW (2C) & 0.91 & 0.0001 & 0.07 & 1.97 & - & NS \\
\hline 3Cw & 0.99 & 0.0001 & $-0.22^{\star}$ & 0.53 & - & NS \\
\hline $3 \mathrm{Cb}$ & 0.81 & 0.001 & 0.69 & 3.11 & - & NS \\
\hline
\end{tabular}

* Bias statistically significant different from zero $(P<0.05$, one-group two-tailed t-test).

significant relation between the difference in $\% \mathrm{BF}$ as calculated with the $4 \mathrm{C}$ and $2 \mathrm{C}$ models and the hydration of the FFM $\left(\mathrm{R}^{2}: 0.54, P<0.05\right)$.

In general, results of the statistical analyses between the standard $4 \mathrm{C}$ model and the other models for FFM are comparable to the \% BF results. Additionally, the differences between the FFM values measured and calculated by the BMI, DXA, D2O, and $3 \mathrm{Cb}$ models and the FFM values based on the reference $4 \mathrm{C}$ model were significantly related to the size of their compartment (mean values, Table 2).

Intervention: body composition changes. Average changes in $\% \mathrm{BF}$ as calculated by the $4 \mathrm{C}$ model were $-1.6 \%$ (range: -5.0 to $1.2 \%$ ), and for the FFM $+3.7 \mathrm{~kg}$ (range: -0.6 to $7.7 \mathrm{~kg}$ ) (Table 3). The biases of the alternative methods were in general not large, with exception of the bias of the BMI-based method (Table 4). Changes in \%BF by the alternative methods were significantly correlated with the changes from the $4 \mathrm{C}$ model, except for the $\% \mathrm{BF}$ changes calculated with the prediction equation based on BMI measurements.

For the BMI-based methods and the $3 \mathrm{Cb}$ model, the individual differences were related to the size of the compartment (Table 4). Relatively large biases were evident for the BMI- (2.6\%), and BIA-based methods $(1.5 \%)$, whereas the lowest bias was observed for the $3 \mathrm{Cw}$ model $(0.3 \%)$. The errors were largest for the BIA-based method (6.28\%) and lowest for the $3 \mathrm{Cw}$ model $(0.69 \%)$

Neglecting the relations between difference and means for the BMI- and $3 \mathrm{Cb}$ models, all individual differences between the results obtained by the alternative methods and the reference method are plotted in Figure 4. The result from the $3 \mathrm{Cw}$ model combines a small bias with a small error. The other three-compartment model $(3 \mathrm{Cb})$ showed a much larger bias and error compared to the $3 \mathrm{Cw}$ model. Differ-

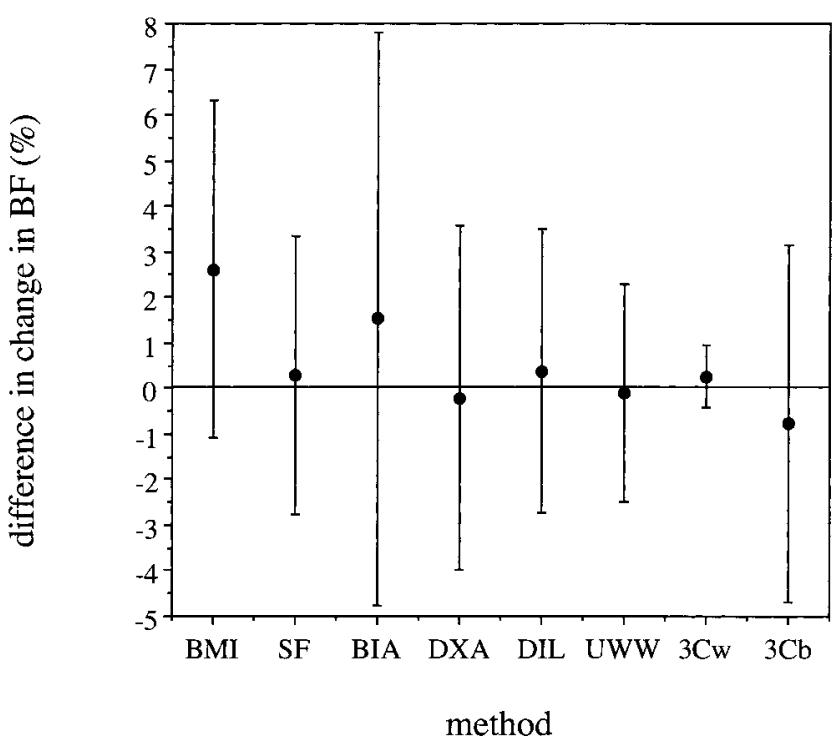

FIGURE 4-Mean differences (dots) and their errors (2 SD; vertical lines) between the \% BF changes as calculated in the intervention study by the $4 \mathrm{C}$ model and the alternative methods. BMI, body mass index; SF, skinfolds; BIA, bioimpedance; DXA, dual x-ray absorptiometry; dil, dilution by deuterium; uww, underwater weighing; $3 \mathrm{Cw}$, threecomponent model with body water; $3 \mathrm{Cb}$, three-component model with body minerals.

ences in \% BF changes calculated by the $4 \mathrm{C}$ and $2 \mathrm{C}$ models were significantly related to the changes in FFM hydration $\left(\mathrm{R}^{2}: 0.73, P<0.01 ;\right.$ Fig. 5). The relation was not significant with TBMD as independent variable.

The results for FFM changes calculated by the alternative methods and compared with the $4 \mathrm{C}$ model were comparable to the results for the \%BF changes (Table 4).

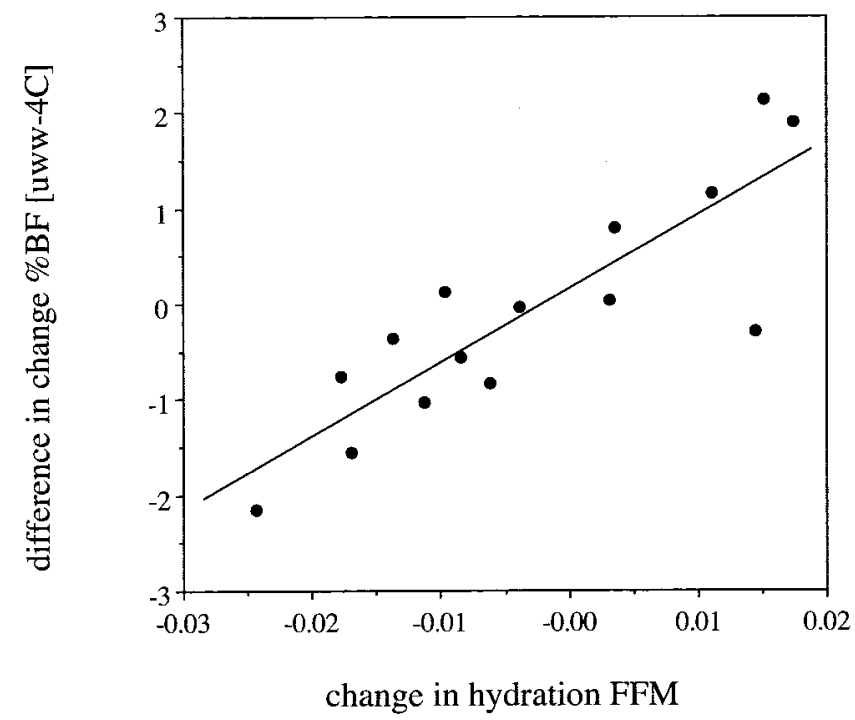

FIGURE 5-Differences in \% BF changes as calculated by the 4C model and 2C model (by uww) plotted against the changes in FFM hydration $\left(\Delta\right.$ change $\% \mathrm{BF}=76.9$ change hydration $+0.148, \mathrm{R}^{2}: 0.74$, $P<0.01)$. 


\section{DISCUSSION}

General findings. Using the four-compartment model as the reference model, substantial differences with various alternative methods to determine the proportion of body fat in bodybuilders were found. The conventional gold standard densitometry on average gave comparable results to the $4 \mathrm{C}$ model, but individual differences were substantial, especially due to differences in hydration of the FFM. The mechanistic methods had errors smaller than 3.5\%BF. The $3 \mathrm{Cw}$ model, combining underwater weighing and deuterium dilution as described by Siri (22) gave the best results with an error of less than $1 \%$. Typically, errors were largest in the descriptive methods (based on BMI, SF, BIA, and DXA measurements), ranging from 5.5 to $8 \%$. This indicates that the use of these methods in individual bodybuilders is not reliable. Body composition changes after intervention are best tracked by the $3 \mathrm{Cw}$ model (small bias of $0.3 \%$ body fat, small error of $0.69 \%$ body fat).

In conclusion, when accurate measurements of body fat and body fat changes are required on an individual level, the $3 \mathrm{Cw}$ model can be used as a good alternative for the $4 \mathrm{C}$ model.

These results apply to a typical subject group, that is, bodybuilders. Other populations may have different mineral and water fractions of the FFM. However, the principles discussed are generally applicable.

Cross-sectional study. Though the $4 \mathrm{C}$ model served as a reference model, it is not an independent model for some of the other methods used. The $4 \mathrm{C}$ model includes measurements of the $2 \mathrm{C}$ (densitometry), $3 \mathrm{Cb}$ (densitometry, bone measurement), $3 \mathrm{CW}$ (densitometry, TBW measurement), and deuterium dilution (TBW measurement) methods. Finally, the DXA scan encompasses both bone mineral characteristics (used in the $4 \mathrm{C}$ model) as well as body fat, which are not fully independent either.

Because the mean density of the FFM (dFFM) is not significantly different from the $1.1 \mathrm{~g} \cdot \mathrm{mL}^{-1}$ that is used in the Siri equation for the $2 \mathrm{C}$ method, it is not surprising that the results of the $2 \mathrm{C}$ model are in close agreement to those of the $4 \mathrm{C}$ model (low bias of $-0.07 \% \mathrm{BF}$, Table 2). $\% \mathrm{BF}$ as calculated with the $3 \mathrm{Cw}$ model is somewhat elevated compared with calculation with the $4 \mathrm{C}$ model, and the use of the $3 \mathrm{Cb}$ model revealed a much lower mean $\% \mathrm{BF}$. The somewhat high fat value resulting from the $3 \mathrm{Cw}$ model is caused by the relatively low BMC of the FFM (6.5\%) in spite of the high bone mineral densities found in these subjects. The relatively low fat estimate of the $3 \mathrm{Cb}$ models is caused by the low hydration of the FFM (mean $72.5 \%$ ) relative to the normal reference population $(73.8 \%(22))$. Earlier it has been found that indeed weight lifters have a relatively low mineral percentage of the FFM (5.3\%) compared with controls (mineral percentage FFM: 5.9\%) (20). Modlesky et al. (20), however, found a relatively high hydration of the FFM (74.8\%). On the other hand, a study on female bodybuilders revealed a higher density of the FFM due to high bone mineral fraction (3). In general, we found lower hydration and higher mineral percentages of the FFM than the study of
Modlesky et al. Apart from actual differences between subjects, this can be explained by slightly different assumptions and calculations. Differences between the two studies with respect to relative contribution of minerals in the FFM can also be caused by differences in DXA machines. The Lunar DPX-L (software 1.3z) used in this study has been found to measure total BMC as much as $15 \%$ higher than the densitometer by Hologic (QDR1000/W, software 5.55) used in Modlesky's study (25). Differences in hydration can also be caused by differences in isotope equilibration time used $(17,24)$.

In general, both bias and errors in $\mathrm{BF}$ determinations with the different mechanistic methods $\left(\mathrm{D}_{2} \mathrm{O}\right.$ dilution, two- and multi-compartment models) is small but not for the $3 \mathrm{Cb}$ model. This can be explained by the fact that the variation in hydration has a large effect on the outcome. In the $3 \mathrm{Cw}$ model, correction for hydration takes place, whereas this is not the case for the $3 \mathrm{Cb}$ model. The fact that the $2 \mathrm{C}$ model gives good results is due to the opposite (compensating) effects of the relatively low hydration of the FFM and low bone mineral fraction of the FFM. BF results obtained with the dilution technique were slightly higher than calculated with the $4 \mathrm{C}$ model. This can be attributed to the relatively low hydration rate of the FFM.

Deviations in $\mathrm{BF}$ results obtained with the $4 \mathrm{C}$ method and those measured with the descriptive methods are substantial. Bias is largest (5.33) with the BMI estimate, which is evidently not the method to determine $\mathrm{BF}$ in bodybuilders and most other strength-trained athletes. A high body mass of the reference men results in a higher body fat percentage, as predicted by the formula, than is the case in bodybuilders. The error is also large, because the group we studied was quite inhomogeneous with respect to body fat content. Mean $\% \mathrm{BF}$ based on skinfolds measurements had a relatively small bias $(0.17 \%)$, but the error was large $(7.92 \%)$. This means that for group analyses the skinfolds can be used for the $\mathrm{BF}$ assessments but not for individual measurements. The error of the BIA-based method was comparable, but the bias was larger than that of the method based on skinfolds. Clearly, BIA measurements add extra accuracy to the data obtained by the prediction equation based on BMI but not to the use of skinfolds.

Body fat proportions based on DXA were higher than those calculated with the $4 \mathrm{C}$ model. Moreover, the error was relatively high, compared with the other mechanistic methods used. In theory, DXA measurements should be less affected by body density. However, variation in the water fraction of the lean soft tissue and errors linked to differences in tissue thickness and the inability to assess soft tissue over or under bone may cause errors in fat contents based on DXA (13). Moreover, like the DXA values for bone minerals, FM differences between machines from different companies are reported (7).

Body composition changes. Few validation studies of body composition changes using the $4 \mathrm{C}$ model have been reported. No such studies are available in strength training.

Overall, results from the intervention study are comparable to those of the cross-sectional study. That means that the 
mechanistic methods have smaller errors with respect to changes in \%BF and FFM than the descriptive methods. It should be kept in mind, however, that the different mechanistic methods presented are not fully independent of each other. Table 4 and Figure 4 clearly demonstrate that for the small changes in \% BF (average $1.2 \%$ ) as observed in the present study, only the $3 \mathrm{Cw}$ method is accurate enough. Of the descriptive methods, the skinfold-based method has the lowest error. For FFM assessments the $3 \mathrm{CW}$ model gives the best results again, followed by skinfolds and the $2 \mathrm{C}$ model.

The difference between the $2 \mathrm{C}$ model and the $4 \mathrm{C}$ model can be explained to a large extend by changes in hydration

\section{REFERENCES}

1. Altman, D. G., and J. M. Bland. Measurement in medicine: the analysis of method comparison studies. The Statistician 32:307317, 1983.

2. Brozek, J., F. Grande, J. T. Anderson, and A. Keys. Densitometric analysis of body composition: revision of some quantitative assumptions. Ann. N.Y. Acad. Sci. 110:113-140, 1963.

3. Bunt, J. C., S. B. Going, T. G. Lohman, C. H. Heinrich, C. D. Perry, and R. W. Pamenter. Variation in bone mineral content and estimated body fat in young adult females. Med. Sci. Sports Exerc. 22:564-569, 1990.

4. Deurenberg, P., D. K. K. van, R. Leenen, J. A. Weststrate, and J. C. Seidell. Sex and age specific prediction formulas for estimating body composition from bioelectrical impedance: a crossvalidation study. Int. J. Obes. 15:17-25, 1991.

5. Deurenberg, P., J. A. Weststrate, and J. C. Seidell. Body mass index as a measure of body fatness: age- and sex-specific prediction formulas. Br. J. Nutr. 65:105-114, 1991.

6. Durnin, J. V. G. A., and J. Womersley. Body fat assessed from total body density and its estimation from skinfold thickness: measurements on 481 men and women aged from 16 to 72 years. Br. J. Nutr. 32:77-97, 1974.

7. Fogelholm, M. and W. D. v. Marken Lichtenbelt. Review. Comparison of body composition methods: a literature analysis. Eur. J. Clin. Nutr. 51:495-503, 1997.

8. Fuller, N. J., S. A. Jebb, M. A. Laskey, W. A. Coward, and M. ELIA. Four-component model for the assessment of body composition in humans: comparison with alternative methods, and evaluation of the density and hydration of fat-free mass. Clin. Sci. 82:687-693, 1992.

9. Fuller, N. J., M. A. Laskey, and M. Elia. Assessment of the composition of major body regions by dual-energy X-ray absorptiometry (DEXA), with special reference to limb muscle mass. Clin. Physiol. 12:253-266, 1992.

10. Hervey, G. R., I. Hutchinson, A. V. Knibis, et al. Anabolic effects of methandienone in men undergoing athletic training. Lancet 2:699-702, 1976

11. Hervey, G. R., A. V. Knibbs, L. Burkinshaw, et al. Effects of methandienone on the performance and body composition of men undergoing athletic training. Clin. Sci. 60:457-461, 1981.

12. Holma, P. Effect of an anabolic steroid (methandienone) on central and peripheral blood flow in well-trained male athletes. Ann. Clin. Res. 9:215-221, 1977.

13. Kohrt, W. M. Body composition by DXA: tried and true? Med. Sci. Sports Exerc. 27:1349-1353, 1995. of the FFM (Fig. 5). Changes in FFM hydration are commonplace during strength training and can partly be attributed to changes in blood volume (10-12).

Thus, as with the cross-sectional values, it can be concluded that when accurate measurements are needed on an individual level, the $3 \mathrm{Cw}$ model could serve as an alternative for the $4 \mathrm{C}$ method. None of the other methods is accurate enough to detect small changes in \%BF and FFM on an individual level.

We thank Loek Wouters for the deuterium analyses, Lia van lersel from the Department of Nuclear Medicine of the University Hospital Maastricht for carrying out the DXA measurements, and Gerard Hornstra for critically reading the manuscript.

14. Lohman, T. G. Advances in Body Composition Assessment, 1 st Ed. Champaign, IL: Human Kinetics, 1992, 150 pp.

15. Lukaski, H. C., W. W. BolonchuK, C. B. Hall, and W. A. Siders Validation of tetrapolar bioelectrical impedance method to assess human body composition. J. Appl. Physiol. 60:1327-1332, 1986.

16. Marken Lichtenbelt, W. D. v., and M. Fogelmholm. Body composition. In: Regulation of Food Intake and Energy Expenditure, M. S. Westerterp-Plantenga, A. B. Steffens, and A. Tremblay (Eds.). Milan: EDRA, 1999, pp. 383-404.

17. Marken, Lichtenbelt, W. D. v., K. R. Westerterp, and L. WoutERS. Deuterium dilution as a method for determining total body water: effect of test protocol and sampling time. Br. J. Nutr. 72:491-497, 1994.

18. Marken, Lichtenbelt, W. D. v., K. R. Westerterp, L. Wouters, and S. C. M. LuIJENDIJK. Validation of bioelectrical-impedance measurements as a method to estimate body-water compartments. Am. J. Clin. Nutr. 60:159-166, 1994.

19. Mazess, R. B., H. S. Barden, J. P. Bisek, and J. Hanson. Dualenergy x-ray absorptiometry for total-body and regional bonemineral and soft-tissue composition. Am. J. Clin. Nutr. 51:1106$1112,1990$.

20. Modlesky, C. M., K. J. Cureton, R. D. Lewis, B. M. Prior, M. A. Sloniger, and D. A. Rowe. Density of the fat-free mass and estimates of body composition in male weight trainers. J. Appl. Physiol. 80:2085-2096, 1996.

21. Schoeller, D. A., E. Van Santen, D. W. Peterson, W. Dietz, J. JASPEN, and P. KLEIN. Total body water measurements in humans with ${ }^{18} \mathrm{O}$ and ${ }^{2} \mathrm{H}$ labelled water. Am. J. Clin. Nutr. 33:2686-2693, 1980.

22. SIRI, W. E. The gross composition of the body. In: Advances in Biological and Medical Physics, C. A. Tobias and J. H. Lawrence (Eds.). New York: Academy Press, 1956, pp. 239-280.

23. Wang, Z. M., S. HeshKa, R. N. Pierson Jr., S. B. Heymsfield. Systematic organization of body-composition methodology: an overview with emphasis on component-based methods. Am. J. Clin. Nutr. 61:457-465, 1995.

24. Westerterp, K. R., W. D. v. Marken Lichtenbelt, and L. WoutERS. The Maastricht protocol for the measurement of body composition and energy expenditure with labeled water. Obes. Res. 3:49-57, 1995.

25. Yetman, K. A., R. D. Lewis, B. Rose, L. B. Rosskopf, T. K. Snow, and P. B. Sparling. Comparison of bone mineral and soft tissue between lunar DPX-L and Hologic QDR-1000W in men (Abstract). Med. Sci. Sports Exerc. 27:S221, 1995. 